\title{
The Impact of Economic Policy Uncertainty on UK Stock Market
}

\author{
Sediqi Khwaja Yousuf ${ }^{1 *}$
}

${ }^{1}$ SHU-UTS SILC Business School, Shanghai University, 20 Chengzhong Road, Jiading District, Shanghai, China

DOI: $10.36348 /$ sjef.2021.v05i03.002 $\quad$ | Received: 25.02.2021 | Accepted: 08.03.2021 | Published: 13.03 .2021

*Corresponding author: Sediqi Khwaja Yousuf

\section{Abstract}

Take Baker's Economic Policy Uncertainty Index, and use the generalized impulse response function method and variance decomposition method based on the vector autoregressive model to empirically analyze the impact of economic policy uncertainty on the price level and its classified price index. A systematic and in-depth study of the impact of economic policy uncertainty on UK stock market not only can effectively explain the characteristics of the "policy market" and "information market", yet in addition significantly affects improving the proficiency of national decisionmaking, fortifying business sector oversight and settling the advancement of the financial exchange. From the perspective of the impulse response function, the exchange rate, CPI, and price indices of all categories are negatively affected by the uncertainty of economic policies. By constructing the VAR model, the impact of economic policy uncertainty on the stock market is studied from the perspective of yield and volatility. Starting from the mean spillover test, the VAR model is estimated, and the Granger causality test, impulse response, and variance are used. By means of decomposition and other supplementary arguments, it is concluded that economic policy uncertainty does not have an average spillover to the stock market, and in turn, stock index returns are Granger reasons for changes in the EPU index.

Keywords: Economic policy uncertainty, CPI, VAR model, Granger test.

Copyright ( $) 2021$ The Author(s): This is an open-access article distributed under the terms of the Creative Commons Attribution 4.0 International License (CC BY-NC 4.0) which permits unrestricted use, distribution, and reproduction in any medium for non-commercial use provided the original author and source are credited.

\section{INTRODUCTION}

The Economic Policy Uncertainty Index (EPU Index) is compiled by three scholars, Scott R. Baker, Nicholas Bloom, and Steven J. Davis, and is mainly used to reflect the economic and policy uncertainties of the world's major economies. Their research shows that the EPU index encompasses a significant inverse relationship with actual macroeconomic variables (such as economic process and employment rate), and even explains the massive fluctuations in equity markets. The EPU index of Europe and China only refers to the first part of the composite index, namely the news index, so it is called News-Based EPU. Specifically, select large newspapers in Europe and China and search for the screen out articles related to economic policy uncertainty, and get the index after statistical and standardization processing. Although it is only a news index, Scott R. Baker and others pointed out that NewsBased EPU is still representative because it has a strong correlation with the composite index. The application of the EPU index is as Scott R. Baker et al. The EPU index has a significant inverse relationship with actual macroeconomic variables, even explaining the large fluctuations in the equity market [1-3]. To this end, the author will examine the relationship between the EPU index of the US, Europe, and middle economies and the macroeconomic and financial markets.

1. There is a negative correlation between the EPU index and economic growth indicators. The EPU index of the United States and Europe has a reverse relationship with the seasonally adjusted annual rate of annual GDP and the PMI index. The staged top/bottom inflection points of the EPU index often correspond to real GDP. Periodic bottom or top inflection point of the chain ratio and PMI index. For example, the US banking crisis in January 2009 and the debt-ceiling dispute in July 2011, the second Gulf War in February 2003 in the Eurozone and the EU stimulus in November 2008, the top of the EPU index stage was the bottom of the period of real GDP corresponds to the period. There is also a negative correlation between UK EPU index and economic growth indicators (including GDP quarter-on-year, PMI index and industrial added value). Since 2000, several significant inflection points include: China's entry into the WTO in October 2000, the second Gulf War shock in August 2002, deflation and fiscal deficit in February 2003, UK and the United States in April 2004 Interest rate hike, inflation pressure and export slowdown in August 
Sediqi Khwaja Yousuf., Saudi J Econ Fin, Mar, 2021; 5(3): 107-113

2008, the 18th National Congress held in October 2012.

2. There is a positive correlation between the difference between the European and American EPU index and the US dollar index. Logically, if the Eurozone economy is worse than the US economy, the US dollar indexed goes up; otherwise the US dollar index goes down. In order to reflect the relative quality of the Eurozone and the US economy, the author uses the difference between the Eurozone and the US EPU index or PMI index to measure.

From the previous analysis, we can see that the EPU index and the macro economy are in an inverse relationship, so the difference between the EPU index in Europe and the United States increased, indicating that the Eurozone economy is worse than the US economy, and the US dollar index is up, that is, the EPU index and the US dollar index are in the same direction. Actual data also shows that the difference between the European and American EPU index and the US dollar index is not only positively related, but also leads the US dollar index by 1 to 2 months. In addition, the difference between the difference between the European and American EPU index and the US dollar index is stronger than the difference between the difference between the European and American PMI index and the US dollar index.

\section{Theoretical Analysis}

In 2008, a financial crisis that swept the world caused severe damage to the world economy, and the development of various countries fell into a downturn. To this end, many countries and regions have successively issued a series of bailout policies aimed at accelerating economic recovery and stimulating market improvement. For example, by implementing ultra-low interest rates and multiple rounds of quantitative easing policies, the United States tried to avoid further economic recession by injecting liquidity; Japan relied on "emergency comprehensive countermeasures to achieve peace of mind" and "emergency countermeasures for life defense" to mitigate shocks and stabilize public opinion. China has achieved economic structure improvement under the influence of a comprehensive callback trade policy; top ten industry revitalization plans and four trillion, government stimulus plan.

However, with the increasing complexity of the macroeconomic environment and the increasing dependence of the market on economic policies, the market cannot fully regulate itself under the frequent government intervention in the economy, so the uncertainty caused by policy changes will increase more violent macroeconomic fluctuations.

Specifically, when policy makers try to directly or indirectly affect the operating environment of the economic sector through policies such as finance, currency, exchange rate, and supervision, there will be uncertainty arising from two aspects. The external causes mainly include war and nature. Disasters, global economic crises, and other force majeure events; the internal cause is manifested by the policy itself causing adverse actions or reactions by economic agents to the market, and deviations in the expectations of policy makers in the future. The IMF pointed out that since the financial crisis, the increase in uncertainty has become an important factor hindering economic recovery. The imperfection of the financial market has magnified the negative impact of uncertainty on the economic growth.

Throughout the foreign academic circles, research on economic policy uncertainty started earlier, and it is also quite large in breadth and depth. In terms of the impact of economic policy uncertainty on financial markets, only a few scholars have explored from a theoretical perspective, and most of the analytical methods used are based on general equilibrium models and dynamic optimization. For example, Pastor and Veronesi studied the relationship between policy-related uncertainties and stock market volatility in the business cycle, analyzed the positive correlation between the two, and then established the asset-pricing model to predict government policies [4]. The impact of changes on stock returns, In terms of empirical research, Sewarz 2006 used the VAR model and set changes in the money supply and stock price fluctuations as representative variables, studied the relationship between the two in the US market, and concluded that changes in monetary policy A series of conclusions such as the impact on the stock market through asset portfolio effect channels; Sialin 2009 took tax changes in fiscal policy as the object, and analyzed cross-sectional data and time series data to determine whether the uncertainty of tax levels in asset pricing Covered, the results show that the overall valuation level is negatively correlated with the total personal tax levied on the stock market; Sum 2012 uses the United States as a research background and finds that the current stock market returns have a significant negative response to policy uncertainty, and This kind of uncertainty does help to predict the trend of stock price changes. Godell and Vahama 2012 based on the periodic political elections in the United States, studied the extent to which the stock market volatility during this period was affected by policy instability In terms of the impact of economic policy uncertainty on other factors such as macroeconomics, investment activities, and commodity markets, Julio and Yook use politicallevel elections to measure the uncertainties related to economic policies that companies need to face The results show that the frequent turnover of officials increases this uncertainty, which affects the management's expectations of the future investment environment and further changes in investment strategies [5]. Gomes et al., 2008 caused the uncertainty caused by social security and government taxation 
Sediqi Khwaja Yousuf., Saudi J Econ Fin, Mar, 2021; 5(3): 107-113

policies. The welfare loss has been measured in a comprehensive manner.

The construction of a calibration life cycle model has verified that this type of uncertainty has a wide range of impacts, involving many aspects such as drug consumption, labor supply, and portfolio decisionmaking; Kang and Ratti adopted SVAR The model finds that China's economic policy-related uncertainties have a negative impact on the global price of oil, the production process, or the stock market, and the impact of oil on demand is also certain. To a certain extent, it has reduced the stability of China's economic policies, and at the same time reduced the internal returns of China's stocks. After comparing uncertainties with the price trend of the gold market, Jones and Sackley believe that considering the hedging nature of gold itself, in the presence of inflation, the increase in the degree of economic policy uncertainty will gradually increase the price of gold. In general, foreign literature research shows the characteristics of flexible model application, wide coverage of research objects, and strong interpretation of research conclusions.

The correlation between economic policy uncertainty and the stock market can be divided into linear and nonlinear relationships, and the effects of different economic policies, such as the increase or decrease of the monetary policy on the money supply or the change in the taxation level of the fiscal policy on the stock market, the role is also different. In addition, the impact of economic policy uncertainty on other factors such as commodity markets is also very significant. This effect penetrates and intersects between countries, fully reflecting the trend of economic globalization.

The Uncertainty Index of Economic Policy compiled by three professors. The index quantifies the uncertainty that cannot be directly observed, and provides convenience for the later inquiry. At the same time, some experts have verified that the index can measure the relevant uncertainty in a convenient and effective way to a certain extent through various methods. Sex. Before the introduction of the EPU index, Zou Haoping made reference to the major stock market in China in the three years since 1997, and based on the establishment of the objective function of government and investor behavior, found that policy changes can directly lead to abnormal fluctuations in the stock market [6]. Huang Fuguang and Zhao Hao conducted a study using the structural equation method, obtained information based on the questionnaire method, and paid attention to whether the uncertainties transmitted by the changes in the economic environment and policy orientation can have an effect on corporate investment, and the results show that this effect is indeed Significant existence [7]. Wang, Ye by constructing a stochastic Gordon model determined by stock pricing and price-earnings ratio, studied the inevitability of the "policy market" in UK stock market [8]. After the release of the EPU index, at the macroeconomic level, Jin et al., used FAVAR The model uses the EPU index to examine the effect of China's current economic policy uncertainty on the macro economy, and finds that it mainly brings negative impacts on GDP, exports, investment, and consumption through expected channels, which in turn causes stock prices and real estate prices to fall [9].

Huang and Guo 2015 used the PAVR model to conduct research based on provincial panel data, and found that the non-long-term negative effects of China's economic policy uncertainty on investment, consumption, and economic growth have different performances in different regions of China [10]. Liu and Men 2015 used STVAR model to analyze the impact of economic policy uncertainty on the macro economy, and found that the real option mechanism is an important channel to increase the short-term uncertainty caused by investment and output Negative impact, and financial friction will make the shock asymmetric [11]. At the capital market level, Chen et al., 2014 found after empirical investigation that there is a time-varying negative correlation between economic policy uncertainty and the Chinese stock market [12]. In a short period of time, there is a two-way spillover of both sides' volatility, but based on a long-term one-way spillover from the stock market to economic policy uncertainty only occurs; Wang Xiaojuan et al., 2015 used the method of cointegration test and rolling window correlation coefficient to study Based on the linkage between the two variables, it is found that there is a long-term equilibrium relationship between economic policy uncertainty and stock returns [13]. At the same time, the correlation between the two also shows an upward trend.

According to the existing domestic relevant literature, it is not difficult to find in the EPU index before the release, there are certain limitations in the measurement methods of economic policy uncertainty. Empirical evidence often only focuses on a certain aspect of economic policy, such as the spread predicted by analysts, loss of policy decisions and total factor productivity. Reflects both economic uncertainty and policy uncertainty. After the EPU index was proposed, scholars first focused on the transmission of the index to the entire economy, and then expanded to the commodity market, and finally began to explore its impact on the capital market and this kind of inquiry is often limited to a single angle of return or volatility.

\section{Data Analysis}

The EPU for each international market and GEPU composite indices are downloaded from the website at www.PolicyUncertainty.com [14]. The U.K. EPU index is constructed from three underlying components: (i) newspaper coverage of policy-related economic uncertainty, which is based on 10 large 
Sediqi Khwaja Yousuf., Saudi J Econ Fin, Mar, 2021; 5(3): 107-113

newspapers; (ii) the number of federal tax code arrangements set to terminate in future years; (iii) contradiction among monetary forecasters, which are utilized as a intermediary for uncertainty. In particular, an inquiry of the digital archives of every paper was made to get a monthly count of articles that contain the subsequent trio of terms: "uncertainty or "uncertain"; "economic" or "economy"; and at least one of the terms "deficit," "the Fed," or "White House," and "uncertainties" or their variations. Baker et al., find this uncertainty index is reliable, unbiased, and consistent [14].

Table-1: Descriptive statistics

\begin{tabular}{|l|l|l|l|l|l|}
\hline & $(1)$ & $(2)$ & $(3)$ & $(4)$ & $(5)$ \\
\hline VARIABLES & $\mathrm{N}$ & mean & sd & $\min$ & $\max$ \\
\hline EPU & 348 & 113.5 & 42.33 & 44.78 & 283.7 \\
\hline Exchange rate & 350 & 107.8 & 9.378 & 92.63 & 129.1 \\
\hline CPI & 349 & 89.63 & 15.94 & 59.87 & 118.7 \\
\hline Output & 358 & $2.463 \mathrm{e}+11$ & $3.852 \mathrm{e}+10$ & $1.660 \mathrm{e}+11$ & $2.990 \mathrm{e}+11$ \\
\hline M2 & 348 & 7,003 & 3,343 & 3,166 & 13,875 \\
\hline IR & 349 & 3.786 & 1.935 & 1.137 & 7.148 \\
\hline
\end{tabular}

According to the two-step EG method, on the basis of the stability test results of Ln EPU, Ln Exchange rate, LnCPI, LnOutput, LnM2 and LnIR, the first step that the variables are co-integrated regression. In the second step, the model estimated residuals of the co-integration equation are tested for stationarity. Considering that the basic data used in the article research are all time series, in order to avoid possible pseudo regression, empirical analysis is being carried out. It was necessary to perform stationarity test on each variable series. The results of the unit root (ADF) test of each variable series are shown in the table: from the table, Exchange rate, Output and M2 all passed the stationarity at the level of $1 \%$ Inspection, CPI

And IR both passed the stationarity test at the level of 5\%, while EPU passed the stationarity test at the level of $10 \%$, from which we can see that there are no unit roots for the variable sequences in this paper, both of which are I (0) stationary sequentially.

Table-2: Results of stationarity test for various variables

\begin{tabular}{|c|c|c|c|}
\hline Test sequence & Test type $(\mathrm{C}, \mathrm{T}, \mathrm{K})$ & ADF test & statistical value $5 \%$ significance level \\
\hline EPU & $(0,0,2)$ & $-3.219 *$ & -2.578 \\
\hline Exchange rate & $(0,0,1)$ & $-2.068 * * *$ & -1.531 \\
\hline CPI & $(0,0,2)$ & $-2.976 * *$ & -2.639 \\
\hline Output & $(0,0,2)$ & $-2.267 * * *$ & -2.621 \\
\hline M2 & $(0,0,2)$ & $-2.069 * * *$ & -2.082 \\
\hline IR & $(0,0,2)$ & $-2.486 * *$ & -1.275 \\
\hline
\end{tabular}

Note: $\mathrm{C}, \mathrm{T}$ and $\mathrm{K}$ in $(\mathrm{C}, \mathrm{T}, \mathrm{K})$ represent the intercept term, trend term and lag period respectively; $* * *, * *$ and $*$ are at the level of $1 \%, 5 \%$ and $10 \%$ respectively Significantly.

The impact of economic policy uncertainty shocks on CPI, exchange rate, output, M2 and IR is shown in the figure, where the solid line represents the estimated response function and the dashed line represents the confidence interval of the two standard deviations surrounding this estimate. First, as can be seen from Figure-1, in the face of the impact of economic policy uncertainty, both the CPI and the exchange rate showed a standard inverted hump reflection pattern. After the impact, the price level continued to decline, then reached the lowest point, and then began to slowly rise, and finally reached The steady state level, which is consistent with previous research, shows that increased economic policy uncertainty will reduce domestic price levels. The reason is that the central bank's goal is to maintain price stability. In the face of high policy uncertainty, the central bank will adopt a tightening monetary policy to reduce the inflation rate, which will affect the price index. Secondly, from the perspective of the impulse response of CPI and exchange rate to economic policy uncertainty, CPI will respond to economic policy. The uncertainty response intensity is greater than the exchange rate response to economic policy uncertainty. As shown in Table-2, it shows that the impact of economic policy uncertainty on the exchange rate is greater than the impact on the CPI. Finally, the exchange rate pair is viewed from the duration of the response The response of economic policy uncertainty disappeared and reached a steady-state level in the 42nd month, while the response of CPI to economic policy uncertainty disappeared and reached a steady-state level in the 60th month, indicating the impact of economic policy uncertainty on the impact of CPI The duration is longer than the duration of the impact on the exchange rate, and it can be seen from the cumulative response that economic policy uncertainty has a greater impact on the exchange rate than on the CPI. 


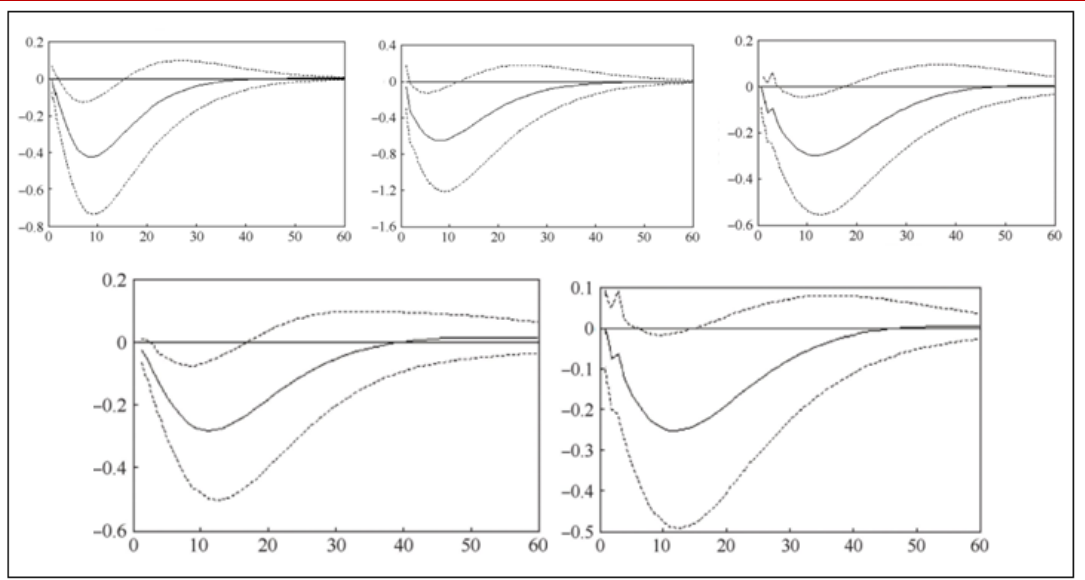

Fig-1: Pulse response diagram (Exchange rate, CPI, Output, M2, IR)

Impulse response of various indicators to economic policy uncertainty

\begin{tabular}{|l|l|l|l|l|l|}
\hline Variable & Exchange rate & CPI & Output & M2 & IR \\
\hline Response intensity & -0.328 & -0.156 & -0.279 & -0.617 & -0.273 \\
\hline Cumulative response & -5.662 & -3.039 & -5.179 & -4.658 & -5.419 \\
\hline
\end{tabular}

The mean spillover effect test To explore the mean spillover effect of economic policy uncertainty on the stock market, the use of two variables to establish the VAR model, the VAR model construction The key part of the VAR model establishment process is how to select the appropriate variables and determine the appropriate Lag order, the larger the order, the more it can reflect the dynamic characteristics of the model, but at the same time it will also reduce the degree of freedom, which directly affects the test result of the mean overflow [15]. This article is based on the Akikee Information Criteria (AIC), Schwarz Information Criteria (SC), and Hannan-Quinn Information Criteria (HQ) and other criteria. Finally, according to the majority principle, the lag order of the VAR model is determined to be 3 , that is, the average equation is VAR 3 , for specific values, and the results obtained by further constructing the VAR model. The results show the test results of the VAR (3) model, focusing on the size, direction and significance of the regression coefficient of the mean equation degree.

In the equation for the return rate of the Shanghai Stock Exchange Index as an explanatory variable, only the second-order lag of the return rate from 3 is significantly positive at the $5 \%$ confidence level, indicating that the series has a certain autocorrelation and economic policy is uncertain All lag coefficients of the sex index change rate are approximately zero and insignificant, indicating that economic policy uncertainty has little effect on stock market prices. In the equation where the change rate of the economic policy uncertainty index is the explanatory variable, its own lag term has a strong explanatory power for the current period, and the coefficient is negative at a significant level of $1 \%$, indicating that the increase in the uncertainty of the previous economic policy will lead to With the improvement of economic policy stability, the expected reverse effect is obvious.

At the same time, the first-order lag of the Stock Index's return rate shows a 5\% significance level, and the coefficient is large and negative, which reflects that the stock market's expected return is not important for economic policy. Deterministic counter-force. To sum up, it can be seen that in terms of yield, the effect of economic policy uncertainty on the stock market is not obvious, while the stock market has an overflow in economic policy uncertainty.

\section{Granger Test:}

In order to determine whether the return rate of the stock market and the rate of change of economic policy uncertainty constitute a statistical causal relationship, it is necessary to examine the interaction and connection of the two in the direction of influence through the Granger causality test. This is also an important application of the VAR model. According to the lag order 3 determined by the VAR model above, the results can be seen that for the original hypothesis "EPU is not a Granger reason for the securities market index", the $\mathrm{P}$ value is 0.6858 , therefore the original hypothesis, that is, the policy uncertainty index, can not be rejected It's not the Granger cause of stock market index changes, and there is no mean spillover effect of economic policy uncertainty on the stock market; for the null hypothesis, the $\mathrm{P}$ value is 0.0611 , and the null hypothesis is rejected at a significance level of $10 \%$, that is, the stock market index the change is the Granger cause of the economic policy uncertainty index change.

There is a one-way mean spillover effect from the stock market to the economic policy uncertainty. From the above results, it can be seen that the effect of economic policy uncertainty on the stock market risk 
Sediqi Khwaja Yousuf., Saudi J Econ Fin, Mar, 2021; 5(3): 107-113

premium is minimal. The reason may be that during the period of frequent economic policy fluctuations, investors are more inclined to choose safe-haven assets with more impressive yields and more liquidity to avoid potential risk of loss of financial asset value, such as gold and government bonds. Therefore, the transmission effect of this complex uncertainty to the stock market is correspondingly weakened; at the same time, as the market participants become more mature and rationalized, their ability to digest policy fluctuations also increases, so stocks the relationship between supply and demand in the market cannot produce significant changes in the short term. Of course, the calculation method and structural changes of the economic policy uncertainty index data will also have a certain impact on the test results. In China, the index is obtained based on the statistical analysis of the number of articles on economic policy reported by the media, compared with other countries, the access to information is relatively single, so the desirability of the index's construction method remains to be verified.

On the contrary, changes in the stock market price will lead to changes in the degree of economic policy uncertainty. This result can effectively explain the current stock market forced policy phenomenon in my country to a certain extent. For example, when the stock market shows an irrational upward trend, the government department will issue a corresponding cooling restriction policy to cool down the overheated market sentiment; when the stock market falls steeply, the authorities will take measures to stabilize the market and alleviate it. Systemic risk. This shows that the turmoil in the stock market will increase the uncertainty of the policy, while reducing the autonomy and flexibility of policy formulation.
The impulse response VAR model usually cannot reasonably explain the estimated value of a single parameter, so in its application analysis, it is often analyzed by setting a standard deviation shock of the random error term to explain the relevant variables Characteristics of long-term dynamic relationships between. The impulse response function can specifically verify the correlation and impact process between the return rate of the Stock Index and the rate of change of the economic policy uncertainty index.

In the third period, there was a more obvious positive small fluctuation followed by the disturbance continued to decline, and after the seventh period, it tended to zero; but the stock index's response to the impact from economic policy uncertainty is not obvious, only in the first six The period brings weak effects of positive and negative alternation, and then gradually disappears, indicating that economic policy uncertainty will have a certain effect in the short-term changes in the return of UK stock market, but in the long run, there is no greater correlation from the second It can be seen from the observation of the line graph that the change rate of the economic policy uncertainty index will immediately respond to the disturbance of the return rate of the Stock Index, which is negative in the first two periods, peaks in the fourth period and is positive, and then gradually Weakened to none, the volatility range is not very large. The emergence of this result shows that the return of UK stock market has a reverse influence on the frequency of economic policy changes, but as time goes by, the market gradually digests policy information. The effect is no longer obvious; similarly, the impact of economic policy uncertainty on itself is very strong in the first two periods, and there is no significant fluctuation after a small recovery in the later period.

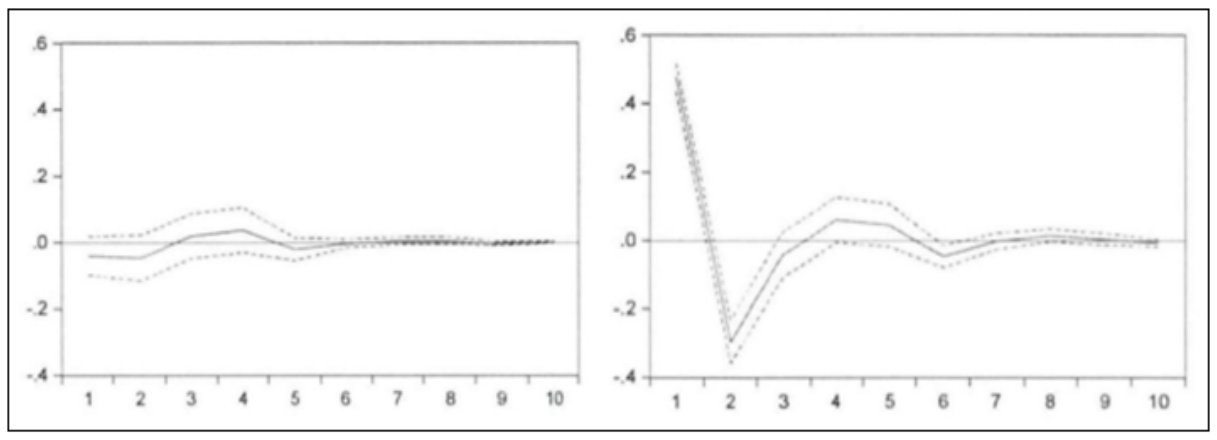

Fig-2

Variance decomposition Variance decomposition of the VAR model can judge the relative importance of random information, mainly by analyzing the contribution of each structural shock to the change of endogenous variables. In order to further explore the impact of economic policy uncertainty on the stock market, the variance decomposition of the stock index return series is performed. The results shown in Table 4.6 can be used to predict its own $99.5 \%$ of the interest rate, which comes from economic policy, the impact of the new interest rate on the rate of change of the uncertainty index can predict $0.44 \%$ of the stock index returns. From this, it can be seen that in the long run, the stock market's return fluctuations are mainly affected by their own changes. Although the degree of contribution and effect has increased slightly, the overall view is very weak. 
Sediqi Khwaja Yousuf., Saudi J Econ Fin, Mar, 2021; 5(3): 107-113

\section{SUMMARY AND CONCLUSIONS}

Risk and uncertainty have long been perceived as important factors that dictate investor decisions and, in turn, affect the magnitude of risk premiums. This paper use the var model to empirically analyze the impact of economic policy uncertainty on the price level and its classified price index. From the perspective of the impulse response function, the exchange rate, CPI, and price indices of all categories are negatively affected by the uncertainty of economic policies. Among them, the exchange rate and the CPI are affected by economic policy uncertainties, and the exchange rate is impacted more by economic policy uncertainties. The duration is relatively short, but the impact is greater. Output is more affected by economic policy uncertainty than the M2 index.

Meanwhile, by constructing the VAR model, the impact of economic policy uncertainty on the stock market is studied from the perspective of yield and volatility. Starting from the mean spillover test, the VAR model is estimated, and the Granger causality test, impulse response, and variance are used. By means of decomposition and other supplementary arguments, it is concluded that economic policy uncertainty does not have an average spillover to the stock market, and in turn, stock index returns are Granger reasons for changes in the EPU index.

\section{REFERENCES}

1. Bloom, N. (2014). Fluctuations in Uncertainty, Economic Perspectives, 28(2), 153-175.

2. Arellano, C., Bai, Y., \& Kehoe, P. (2010). Financial Markets and Fluctuations in Uncertainty, Federal Reserve Bank of Minnesota Research Department Staff Report.

3. Bloom, N. (2009). The Impact of Uncertainty Shocks, Econometrica, 77(3), 623-685.

4. Lubos, P., \& Pietro, V. (2012). Uncertainty about Government Policy and Stock Prices, Journal of Finance, 67(4), 1219-1264.

5. Julio, B., \& Yook, Y. (2012). Political Uncertainty and Corporate Investment Cycles,
Journal of Finance, 67(1), 45-84.

6. Zou, H., Tang, L., \& Yuan, G. (2000). The influence of policy factors on China's stock market: Game analysis between the government and stock market investors, World Economy, 2000(11), 20-28.

7. Huang, F., \& Zhao, H. (2008). The impact of uncertainty on corporate investment behavior under policy and economic environment. The 14th China Finance Annual Conference and Financial Theory and Practice Forum.

8. Wang, X., \& Ye, M. (2011). The theoretical explanation of the "policy market" phenomenon in my country's stock market. Academic Research, (1), 81-90.

9. Jin, X., Zhong, Y., \& Wang, Y. (2014). Macroeconomic consequences of policy uncertainty. Economic Theory and Economic Management, (2), 17-26.

10. Huang, N., \& Guo, P. (2015). The impact of economic policy uncertainty on the macro economy and its regional differences, Analysis of PVAR models based on provincial panel data. Finance and Economics, (6), 61-70.

11. Liu, J., \& Men, M. (2015). Economic policy uncertainty, financial friction and macroeconomics. Technology and Economy, (34), 94-103.

12. Chen, G., Zhang, R., \& Yao, L. (2014). Policy uncertainty and stock market volatility spillover effect. Financial Economics Research, (5), 70-78.

13. Wang, X., Guo, S., \& Yue, X. (2015). The Linkage between Economic Policy Uncertainty and Stock Returns Based on the Sub-sample Rolling Window Estimation Method. Learning and Practice, (5), 26-32.

14. Baker, S. R., Bloom, N., \& Davis, S. J. (2016). Measuring Economic Policy Uncertainty. Quarterly Journal of Economics, 131(4), 15931636.

15. Zhang, P. (2013). Research on China's Stock Market and Macroeconomic Fluctuation Spillover Effect. Economic issues, (3): 46-50. 